\title{
International Business Cycle Synchronization since the 1870s: Evidence from a Novel Network Approach
}

\author{
Nikolaos Antonakakis ${ }^{\mathrm{a}, \mathrm{b}, \mathrm{c}, \mathrm{d}, *}$, Periklis Gogas ${ }^{\mathrm{e}}$, Theophilos Papadimitriou ${ }^{\mathrm{e}}$, Georgios \\ Antonios Sarantitis ${ }^{\mathrm{e}}$ \\ ${ }^{a}$ Vienna University of Economics and Business, Department of Economics, Institute for International \\ Economics, Welthandelsplatz 1, 1020, Vienna, Austria. \\ ${ }^{b}$ University of Portsmouth, Economics and Finance Subject Group, Portsmouth Business School, Portland \\ Street, Richmond Building, Portsmouth, PO1 3DE, United Kingdom. \\ ${ }^{c}$ Webster Vienna Private University, Department of Business and Management, Praterstrasse 23, 1020, \\ Vienna, Austria. \\ ${ }^{d}$ Johannes Kepler University, Department of Economics, Altenbergerstrae 69, Linz, 4040, Austria. \\ ${ }^{e}$ Democritus University of Thrace, Department of Economics, Komotini, 69100, Greece
}

\begin{abstract}
In this study, we examine the issue of business cycle synchronization from a historical perspective in 27 developed and developing countries. Based on a novel complex network approach, the Threshold-Minimum Dominating Set (T-MDS), our results reveal heterogeneous patterns of international business cycle synchronization during fundamental globalization periods since the 1870s. In particular, the proposed methodology reveals that worldwide business cycles de-coupled during the Gold Standard, though they were synchronized during the Great Depression. The Bretton Woods era was associated with a lower degree of synchronization as compared to that during the Great Depression, while worldwide business cycle synchronization increased to unprecedented levels during the latest period of floating exchange rates and the Great Recession.
\end{abstract}

Keywords: Business cycle synchronization, Globalisation, Complex networks, Threshold-Minimum Dominating Set

JEL codes: E3; E32; N10

\footnotetext{
*Corresponding author, email: nikolaos.antonakakis@wu.ac.at, phone: +43/1/313 36-4141, fax: +43/1/313 36-90-4141.

Email addresses: nikolaos.antonakakis@port.ac.uk, nikolaos.antonakakis@webster.ac.at, nikolaos.antonakakis@wu.ac.at (Nikolaos Antonakakis), pgkogkas@ierd.duth.gr (Periklis Gogas), papadimi@ierd.duth.gr (Theophilos Papadimitriou), gsaranti@ierd.duth.gr (Georgios Antonios Sarantitis)
} 


\section{Introduction}

The global economy has experienced several periods of globalization. First, the classical Gold Standard era with relatively free trade and capital mobility. Second, the two World Wars and the Great Depression with trade and capital controls. Third, the Bretton Woods era of fixed, albeit adjustable, exchange rates and limited capital mobility. Fourth, the floating exchange rates and Great Recession period with increased trade and capital integration. These developments have generated a lot of interest and debate about the changing patterns and degree of international business cycle co-movements.

The link between globalization and international business cycle synchronization is theoretically/empirically ambiguous. One the one hand, rising financial and trade linkages could result in a higher degree of business cycle co-movement via the wealth effects of external shocks (see, for instance, Kose et al., 2003; Artis et al., 2011; Kose et al., 2012). On the other hand, rising financial linkages could reduce cross-country business cycle correlations by stimulating specialization of production through the reallocation of capital in a manner consistent with countries' comparative advantage. Similar predictions exist for the link between trade integration and business cycle synchronization. For example, increased trade linkages generate both demand- and supply-side spillovers across countries that can lead to more highly correlated business cycles. Conversely, in the presence of sector-specific shocks, increased trade linkages may facilitate increased specialization of production across countries, which in turn will lead to less synchronized business cycles (see, e.g., Baxter and Kouparitsas, 2005). Besides, other studies have found that business cycle synchronisation between developed countries have decreased in the recent decades, largely on account of a remarkable cycle of de-synchronization in the late 1980s and 1990s (see, for example, Helbling and Bayoumi, 2003; Doyle and Faust, 2005).

The objective of our paper is to examine international business co-movements over fundamental periods of economic globalization. Our analysis is closely related to the empirical literature on business cycle synchronization (e.g. Otto et al., 2001; Kose et al., 2003; Imbs, 2004; Stock and Watson, 2005; Kose et al., 2008; Crucini et al., 2011; Kose et al., 2012) and especially to Artis et al. (2011) and Antonakakis (2012). In contrast to the existing literature, we propose the application of a novel complex network methodology, the ThresholdMinimum Dominating Set, in a sample of 27 developed and developing countries since 1875, which provides us with a bird's eye view on the link between economic globalization and international business cycle synchronization.

Complex Network analysis is a distinct field of applied mathematics that models complicated systems of interacting agents as networks, and then analyzes them with a variety of tools that range from simple descriptive metrics to very advanced and sophisticated clustering and optimization techniques. It was popularized mainly for the analysis of social networks (Milgram, 1967; Freeman, 1979), but also in applications such as metabolic-biological networks (Weng et al., 1999; Schuster et al., 2000), air transportation networks (Guimera et al., 2005), power grids (Pagani and Aiello, 2013) and many more. Eventually the use of complex networks was introduced in the analysis of complex economic systems such as financial networks (Mantegna, 1999; Allen and Gale, 2000; Vandewalle et al., 2001; Bonanno 
et al., 2004; Cajueiro and Tabak, 2008; Papadimitriou et al., 2013) or macroeconomics (Hill, 1999; Garlaschelli et al., 2007; Schiavo et al., 2010; Acemoglu et al., 2012; Papadimitriou et al., 2014). Network analysis offers a multi-level analysis of the underlying system from the macroscopic level to the agent-specific one, and can thus provide an alternative or complementary context to the one of classic econometrics and statistics.

The Threshold-Minimum Dominating Set (T-MDS) methodology that is used in the empirical section of this study is an improvement of the classic Minimum Dominating Set. The classic MDS has been mostly used in computer-based applications and in particular wireless networks' configuration (Wu and Li, 1999; Cheng et al., 2003) and data-mining (Boginski et al., 2006; Shen and Li, 2010). The MDS identifies a sub-graph of the initial network that contains adequate information to describe the collective topology of the entire network using only a minimum fraction of nodes. For this kind of applications and analyses the classic MDS can be applied on the initial network "as is" without prior refinement, since all edges are crucial in the identification of the MDS. However, in an economics network where the edges describe the similarity of the incident nodes (e.g. a correlation-based network or the SCI similarity measure used here), not all edges contain reliable or useful information and thus, should not be included in the MDS identification process. For this reason, a threshold is selected prior to the MDS identification in order to eliminate all irrelevant edges. By doing this, all remaining edges are highly informative and reliable in terms of economic inference.

The contribution of our work to this literature can be summarised as follows. We demonstrate the utility of network analysis and especially the Threshold-Minimum Dominating Set in the analysis of business cycle synchronization in 27 developed and developing countries over the period 1875-2013 by paying particular attention to the dynamic evolution of business cycle synchronisation under several fundamental globalisation periods. To the best of our knowledge only three studies employ network analysis on the topic of business cycle synchronization patterns. These are, Gomez et al. (2012), Caraiani (2013) and Xi et al. (2014). However, the last two conduct only a static analysis that is based on the whole sample under consideration and they do not provide any evidence on the inter-temporal evolution of business cycles synchronization. Gomez et al. (2012), within a dynamic context, employ the Minimum Spanning Tree technique (MST) to study inter-temporal business cycle synchronization. The MST however, suffers an important shortcoming when applied on correlation-based economics networks: the no-loop restriction of the MST identification procedure may lead to sub-optimal solutions and possibly in wrong inference. Our work using the T-MDS overcomes the short-coming of the MST and also provides a dynamic historical analysis of business cycle synchronization that spans four major periods of globalization, namely, 1875-1912 (The Gold Standard), 1913-1944 (WWI, WWII and the Great Depression), 1945-1972 (Bretton Woods) and 1973-2013 (floating exchange rates).

This paper is organized as follows. The proposed methodology and the dataset are presented in Section 2. Results from the application of T-MDS on the selected dataset can be found on Section 3. The paper concludes in Section 4. 


\section{Data and methodology}

\subsection{Data}

We collect annual data on per capita GDP (GDPPC) for 27 developed and developing countries that are listed in Table 1. ${ }^{1}$ The data are expressed in 1990 US dollars (converted at Geary Khamis PPPs) and are available for the period from 1875 to 2013, a total of 139 years.

Table 1: The 27 countries included in the study

\begin{tabular}{ll}
\hline \hline Developed & Developing \\
\hline Austria & Argentina \\
Belgium & Brazil \\
Denmark & Chile \\
Finland & Uruguay \\
France & India \\
Germany & Indonesia \\
Greece & Sri Lanka \\
Italy & \\
Netherlands & \\
Norway & \\
Portugal & \\
Spain & \\
Sweden & \\
Switzerland & \\
United Kingdom & \\
Canada & \\
United States & \\
Japan & \\
Australia & New Zealand \\
\hline \hline
\end{tabular}

The series are obtained from the Total Economy Database of the University of Groningen, which updates the database of Maddison (2003). ${ }^{2}$ Table 2, which presents the descriptive statistics of the real GDPPC series, shows that the increase in output per capita over the last 139 years was accompanied by increased volatility.

\footnotetext{
${ }^{1}$ The use of per capita GDP rather than overall GDP is to control for country size differences and diverging patterns of demographic characteristics that could distort the results, while the choice of the 27 countries is due to data availability.

${ }^{2}$ See http://www.conference-board.org/data/economydatabase/ and http://www.worldeconomics. com/Data/MadisonHistoricalGDP/Madison $\ \% 20 H i$ storical $\ \% 20 G D P \backslash \% 20 D a t a . e f p$.
} 


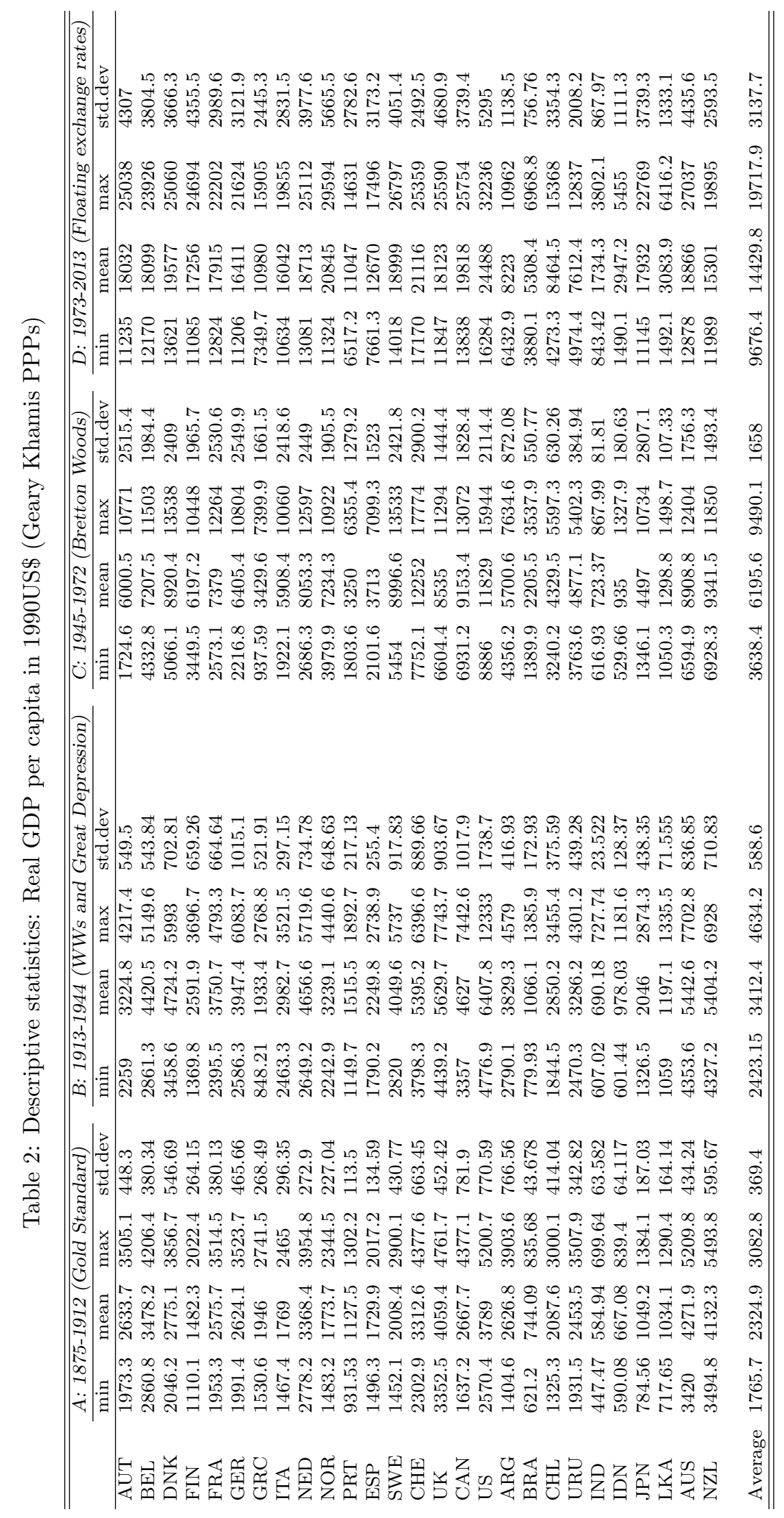


The business cycles of the 27 countries are obtained based on the cyclical components of annual GDPPC in year $t$ defined as the deviation of the logged actual from potential (trend) GDPPC; the latter is obtained from the Hodrick-Prescott filtered series of (the logarithm of) the countries' GDPPC. ${ }^{3}$ These series are shown in Figure 1 below.
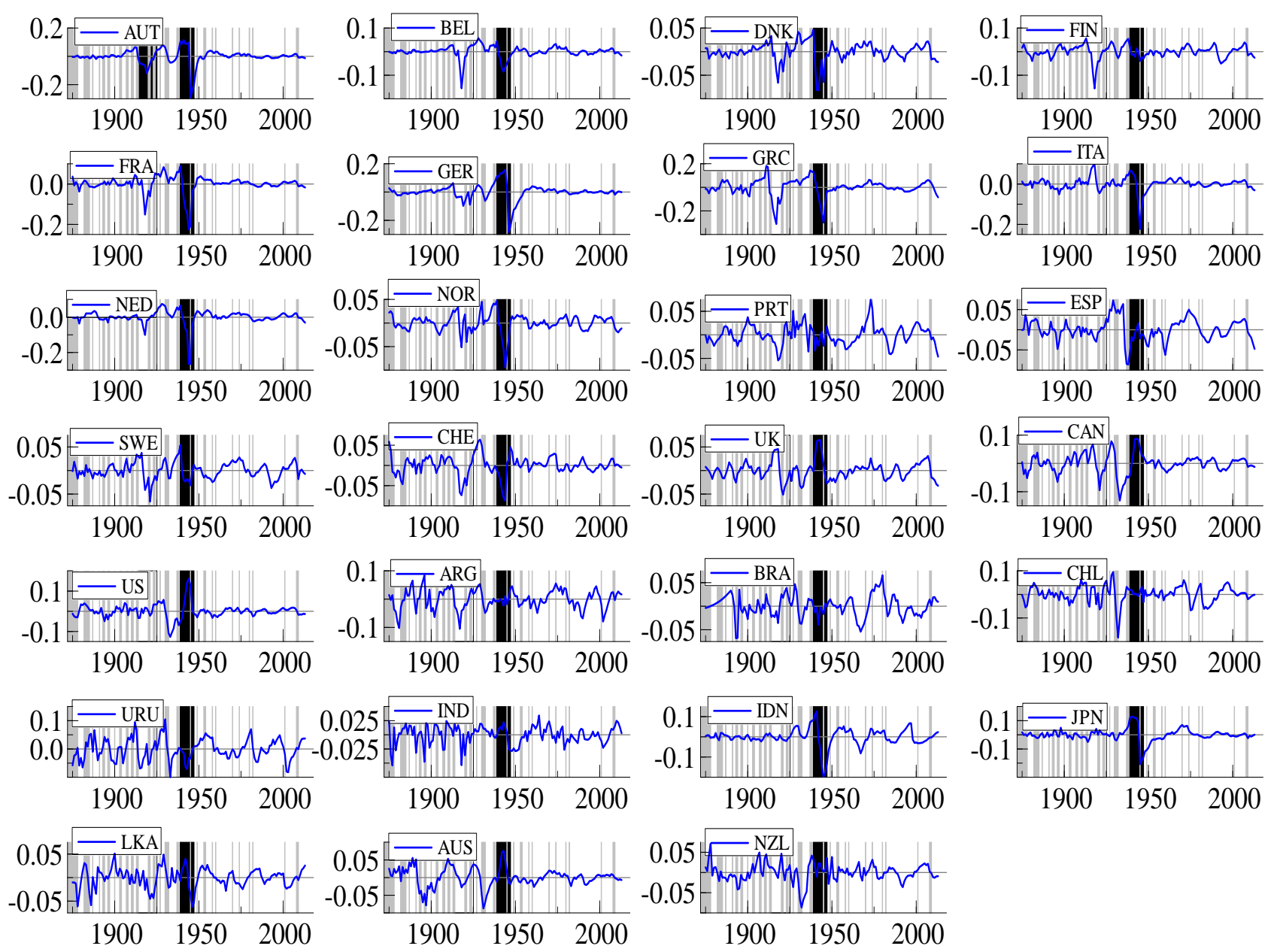

Figure 1: Business cycles, 1875-2013

Note: Black shading denotes world war periods, while grey shading US recessions.

\subsection{Methodology}

\subsubsection{Network construction}

In network analysis, a network (or more formally a Graph) is a collection of nodes $(N)$ linked by edges $(E)$; in mathematical terms $G=(N, E)$. In this study the nodes corre-

\footnotetext{
${ }^{3}$ For robustness, we have also cross-checked the results using GDPPC growth instead of the filtered variables. The findings are qualitatively very similar and thus omitted for the sake of brevity.
} 
spond to the 27 countries under examination while the edges represent the similarity of the countries' GDP cyclical components, calculated with the Sign Concordance Index (SCI). Following Gogas (2013), we select the SCI as a suitable measure of similarity over other more commonly used metrics for the network construction such as Pearson's correlation coefficient. As the author argues, the SCI is more appropriate to capture the inter-temporal synchronization of two countries business cycles as compared to their overall linear correlation which is measured by Pearson's coefficient.

In a window of $T$ observations and for each pair of countries $i, j$ the SCI returns the share of times that both cyclical components are above or below zero (trend), calculated by:

$$
\begin{gathered}
S C I_{i, j}=\frac{\sum_{t=1}^{T} k_{t}(i, j)}{T}, \\
k_{t}(i, j)= \begin{cases}1, & \text { if } \operatorname{sign}\left(c_{i, t}\right)=\operatorname{sign}\left(c_{j, t}\right) \\
0, & \text { if } \operatorname{sign}\left(c_{i, t}\right) \neq \operatorname{sign}\left(c_{j, t}\right),\end{cases}
\end{gathered}
$$

where $c_{i, t}$ is the cyclical component of country $i$ at time $t$. Since the SCI is actually a ratio, it takes values in $[0,1]$. Values near zero indicate extreme business cycle de-coupling whereas SCI values near one provide evidence in favor of a high degree of synchronization.

We construct four networks that correspond to the four consecutive periods under examination, i.e.: The Gold Standard 1875-1912, The Great Depression and the two World Wars 1913-1944, the Bretton Woods 1945-1972, and the floating exchange rates 1973-2013. Then, we employ the T-MDS to analyze these four networks as we describe below.

\subsubsection{Threshold-Minimum Dominating Set}

A simple Dominating Set (DS) is a subset of $N(D S \subseteq N)$ such that all nodes of $G$ either belong to the DS or are directly connected to one or more DS nodes. The Minimum Dominating Set is the DS with the smallest cardinality. To identify a simple DS we start by creating $\mathrm{n}$ binary variables $x_{i}, i=1, \ldots, n$ where $n$ is the total number of nodes in the network, to depict the membership status of each node in the DS:

$$
x_{i}= \begin{cases}1, & \text { if } i \in D S \\ 0, & \text { if } i \notin D S\end{cases}
$$

The DS assumption is expressed through:

$$
x_{i}+\sum_{j \in B(i)} x_{j} \geq 1, i=1, \ldots, n,
$$

where $B(i)$ is the neighborhood of node $i$; the subset of nodes that are directly connected to node $i$. Equation (4) captures the essence of a Dominating Set: each network node can be either (a) a dominant node itself $\left(x_{i}=1\right)$ or (b) adjacent to one or more DS nodes $\left(\exists j \in B(i): x_{j}=1\right)^{4}$

\footnotetext{
${ }^{4}$ This is not an exclusive disjunction: nodes may exist that verify both cases (be a DS node and also adjacent to one or more other DS nodes. The members of the Dominant Set are called Dominant Nodes.
} 
The minimum cardinality condition of the DS is expressed by:

$$
f(\mathbf{x})=\min _{\mathbf{x}} \sum_{i=1}^{n} x_{i}
$$

Thus the identification of the MDS is transformed into minimizing Equation (5) under the constrains in Equation (4).

The MDS can efficiently describe the collective behavior of an entire network by identifying the smallest set of representative agents. In other fields of study (e.g. computer networks) all edges are vital and should be included in the analysis. In an economics network though, not all edges include reliable information and using them in the algorithmic identification of the MDS may produce misleading and inefficient inference. More specifically, for the particular purposes of this study, the SCI is used as the similarity measure of the business cycles. A low SCI indicates that there is a loose synchronization between two countries' cyclical components. Thus, for all practical purposes, those countries' business cycles should be considered dissimilar. The classic MDS algorithm as described above, does not take into account in the minimization procedure the informational content of the edges. In our case the edges carry the SCI information that is crucial for our analysis.

To overcome the above structural inadequacy of the classical MDS we follow Papadimitriou et al. (2014) and we add an extra step before its identification: we impose a threshold on the network's edges so that only the edges that correspond to high degrees of synchronization remain; the edges with an SCI value below the threshold are considered irrelevant and they are removed from the network. By doing this, we ensure that all remaining edges correspond to high SCI values and connect countries with highly synchronized business cycles. The two-step methodology of (a) imposing a threshold on the initial network edges and (b) identifying the MDS on the remaining network is termed Threshold-Minimum Dominating Set (T-MDS).

The imposition of a threshold on the network's edges may lead to the appearance of isolated nodes, i.e. nodes without any interconnection to the rest of the network. In the context of our analysis, the existence of isolated nodes (countries) is evidence that the respective countries present idiosyncratic business cycles. The second step of the T-MDS methodology leads to the identification of the dominant nodes, i.e. the MDS nodes that belong to the interconnected part of the network.

The definition of the T-MDS requires that both the dominant and the isolated nodes are included in it: $T-M D S=I \cup C$, where $I$ and $C$ are the sets of the isolated and the dominant nodes respectively. However, it must be stressed that countries that pertain to isolated nodes present highly atypical behavior and cannot be considered and analyzed in a cohesive way together with the rest of the dominant nodes. The analysis of the two sets should be done separately in order to obtain inference on: (a) the mechanism that drives the emergence of neighborhoods of similarly behaving countries and (b) the patterns of business cycles convergence through time.

In a given network the T-MDS cardinality can range between two extreme values; if the network is complete (all nodes connected to each other) the T-MDS size is 1 with 
every node being a possible unitary T-MDS by itself. In the other extreme, should the network be disconnected (all nodes isolated) the T-MDS size will equal the number of the nodes in the network, as its definition requires. Hence, a T-MDS cardinality close to 0 indicates a rather dense network and a T-MDS cardinality close to 1 corresponds to a sparse network. In our study, the edges pertain to the correlations between the network's nodes (countries' GDP growth rate similarity). Therefore, by calculating the T-MDS for consecutive periods we can infer on the evolution of business cycles similarity levels. An inter-temporally "shrinking" T-MDS will indicate that more edges survive the threshold and that the GDP growth rate correlations are getting stronger, providing evidence in favor of business cycle convergence. On the other hand, an expanding T-MDS size would indicate that GDP growth rate correlations are becoming weaker over time because fewer edges are able to "survive" the threshold, providing evidence in favor of business cycle de-coupling.

\section{Estimation Results}

We perform the T-MDS analysis using a variety of alternative thresholds on the initial network. We observe that the empirical results from all threshold instances are qualitatively similar and thus, for the sake of brevity, we only include in this paper the results according to the $p=0.75$ threshold which are more illustrating and easily comprehensive. ${ }^{5}$

\subsection{Network specific results}

In Table 3 we present for the four globalization periods the following network topology metrics: (a) the T-MDS size, (b) the cardinality of the Isolated nodes set, (c) the cardinality of the Dominant nodes set, (d) the number of network edges and (e) the network density (calculated as the ratio between existing edges and maximum possible number of edges).

Table 3: T-MDS metrics for the threshold instance $\mathrm{p}=0.75$

\begin{tabular}{lcccc}
\hline & $1875-1912$ & $1913-1944$ & $1945-1972$ & $1973-2013$ \\
\hline T-MDS size & 24 & 10 & 14 & 9 \\
Isolated nodes & 22 & 6 & 8 & 5 \\
Dominant nodes & 2 & 4 & 6 & 4 \\
Number of edges & 3 & 41 & 28 & 56 \\
Network Density & 0.01 & 0.12 & 0.08 & 0.16 \\
\hline \hline
\end{tabular}

Our empirical results suggest that as the globalization process progresses, it induces a trend towards a higher degree of synchronization between the 27 countries under consideration. More specifically, in the first period of 1875-1912 the network of 27 countries is

\footnotetext{
${ }^{5}$ We have tested a variety of high threshold levels, ranging from 0.70 to 0.95 with a 0.05 step. Although we report only the $\mathrm{p}=0.75$ results which are more illustrative of our analysis, the rest of the results are available ad hoc.
} 
sparsely connected since 24 of them are totally disconnected (isolated). As the world economy moves from the Gold Standard era to the two World Wars and the Great Depression period (1913-1944), the network becomes much denser as witnessed by the decreased cardinality of the isolated nodes' set and the appearance of 41 new edges in the network (versus only 3 in the first instance), suggesting an increased business cycle synchronization in the latter period. During the Bretton Woods era (1945-1972), worldwide business cycle synchronization appears lower as compared to the Great Depression period. The network edges fall to 28 , the density to 0.08 and the isolated nodes increase to 8 , signaling a completely atypical business cycle of 8 countries while the rest also present more dissimilar behavior. It is noteworthy that the general business cycle de-coupling that is observed in this period does not reach the levels of the initial period of the Golden Standard era. Finally, during the period of floating exchange rates (1973-2013), worldwide business cycle synchronization reaches its highest level as this is expressed through the T-MDS output. The network edges reach 56 (double from the previous period), the Isolated nodes' set cardinality is the lowest across all periods (5) and the network density reaches 0.16 .

Overall, the empirical results from the aggregate network analysis indicate a heterogeneous pattern of business cycle synchronization among the 27 considered countries. The first period (Golden standard era) is associated with the lowest business cycle synchronization degree, the second period (Great depression) brings about convergence, the third period (Bretton Woods) induces diverging patterns and finally the last period of floating exchange rates is associated with the highest degree of business cycle synchronization between the 27 countries across the whole time sample.

\subsection{Country-specific results}

While the main concern of this study is the examination of business cycle convergence patterns in a collective fashion, it is also interesting to explore the inter-temporal behavior of specific individual countries. These are the ones that exhibit a highly idiosyncratic or even opposite behavior in comparison to the rest of the network in specific sub-periods. These results may be useful in the formulation and implementation of macro-economic policies to (further) boost economic integration. In Table 4 we report the countries that present highly atypical business cycles (isolated nodes).

The first striking observation is that two countries fail to connect to the network across all sub-periods. These are Brazil and New Zealand. India also presents an idiosyncratic behavior as it appears isolated in three out of the four globalization periods. It is only a member of the interconnected part of the network for the Bretton Woods era (see also Figure 2 for an optical illustration of the four network instances). As the globalization procedure continues and global economic integration takes place, the countries are expected to eventually synchronize their business cycles. However, after a long period of almost 140 years which our sample covers, these economies do not show any signs of entering this generally expected pattern.

It is also interesting to examine the relative topology of each country in each period of focus. For this reason, in Table 5 below we report the node degrees for the 27 countries in each of the four globalization periods (the degree of a network node is the number of 

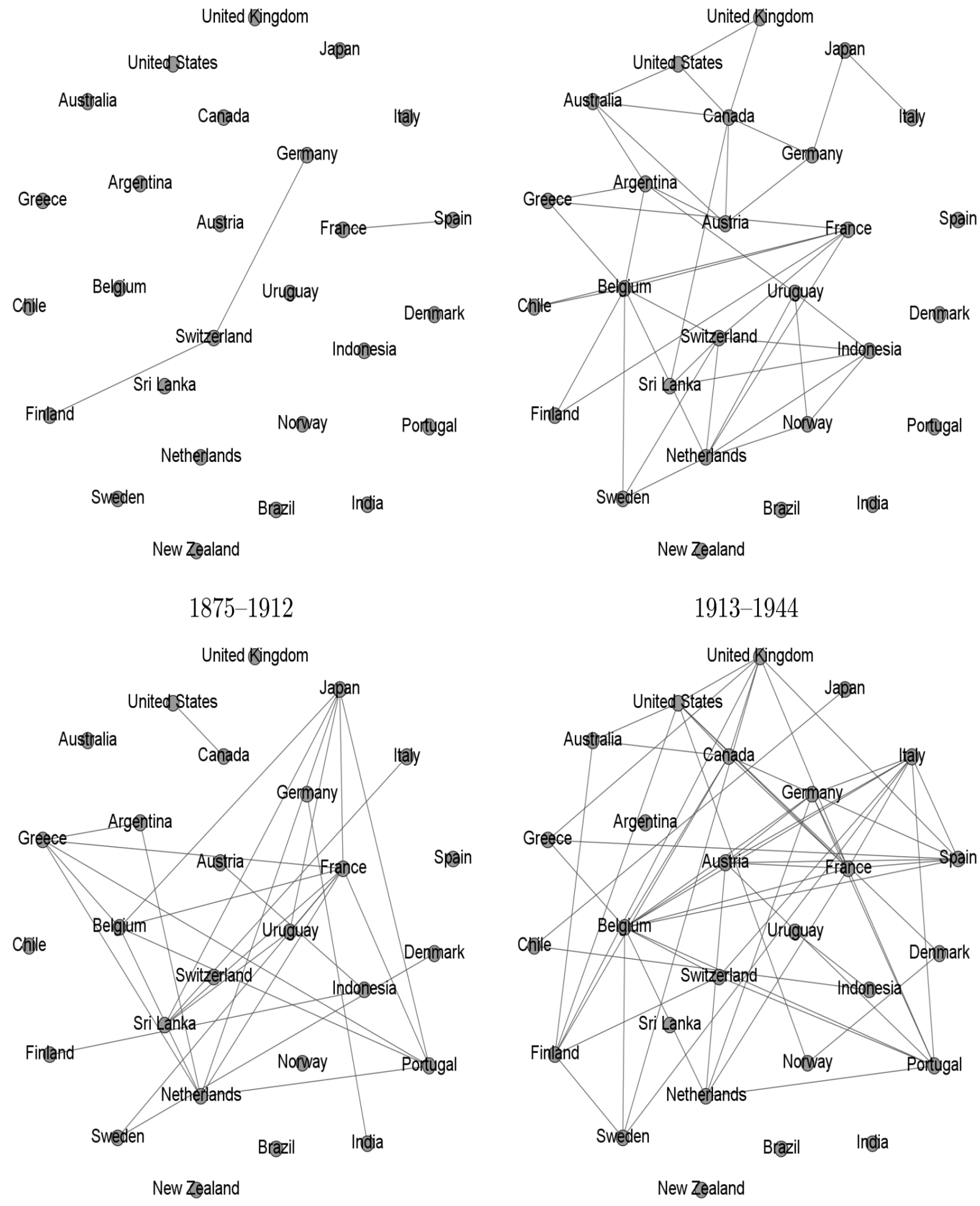

$1945-1972$

1973-2013

Figure 2: The complex networks after the threshold step for the periods: (a) 1875-1912 (b) 1913-1944 (c) 1945-1972 (d) 1973-2013 
Table 4: Isolated countries in each sub-period

\begin{tabular}{l|l}
\hline \hline Period & Isolated countries \\
\hline $1875-1912$ & Austria, Belgium, Denmark, Greece, Italy, Netherlands, Norway, Portugal, \\
& Sweden, United Kingdom, Canada, United States, Argentina, Brazil, Chile, \\
& Uruguay, India, Indonesia, Japan, Sri Lanka, Australia, New Zealand \\
1913-1944 & Denmark, Portugal, Spain, Brazil, India, New Zealand \\
$1945-1972$ & Norway, Spain, Switzerland, United Kingdom, Brazil, Chile, Australia, New \\
& Zealand \\
$1973-2013$ & Argentina, Brazil, India, Sri Lanka, New Zealand \\
\hline \hline
\end{tabular}

Notes: The countries in bold pertain to isolated nodes in all periods of focus (countries with idiosyncratic business cycles).

connections it has to other nodes). Figure 3 contains the same information in a more comprehensive, graphical illustration. The last row of Table 5 corresponds to the average node degree of the network and provides a benchmark in each globalization period. 
Table 5: Node degree during the four globalization periods

\begin{tabular}{lcccc}
\hline \hline & \multicolumn{4}{c}{ Period } \\
Country & $1875-1912$ & $1913-1944$ & $1945-1972$ & $1973-2013$ \\
\hline Austria & 0 & 4 & 1 & 7 \\
Belgium & 0 & 8 & 5 & 11 \\
Denmark & 0 & 0 & 1 & 2 \\
Finland & 1 & 2 & 1 & 6 \\
France & 1 & 6 & 8 & 10 \\
Germany & 1 & 3 & 1 & 6 \\
Greece & 0 & 3 & 5 & 3 \\
Italy & 0 & 1 & 1 & 8 \\
Netherlands & 0 & 7 & 6 & 5 \\
Norway & 0 & 3 & 0 & 2 \\
Portugal & 0 & 0 & 5 & 7 \\
Spain & 1 & 0 & 0 & 7 \\
Sweden & 0 & 3 & 2 & 4 \\
Switzerland & 2 & 6 & 0 & 4 \\
United Kingdom & 0 & 2 & 0 & 7 \\
Canada & 0 & 6 & 1 & 7 \\
United States & 0 & 3 & 1 & 7 \\
Argentina & 0 & 5 & 2 & 0 \\
Brazil & 0 & 0 & 0 & 0 \\
Chile & 0 & 2 & 0 & 2 \\
Uruguay & 0 & 4 & 3 & 1 \\
India & 0 & 0 & 1 & 0 \\
Indonesia & 0 & 5 & 2 & 2 \\
Japan & 0 & 2 & 6 & 1 \\
Sri Lanka & 0 & 3 & 4 & 0 \\
Australia & 0 & 4 & 0 & 3 \\
New Zealand & 0 & 0 & 0 & 0 \\
\hline Average degree & 0.22 & 3.03 & 2.07 & 4.14 \\
\hline \hline & & & & \\
& 0 & 0 & 5 & 2 \\
\hline
\end{tabular}



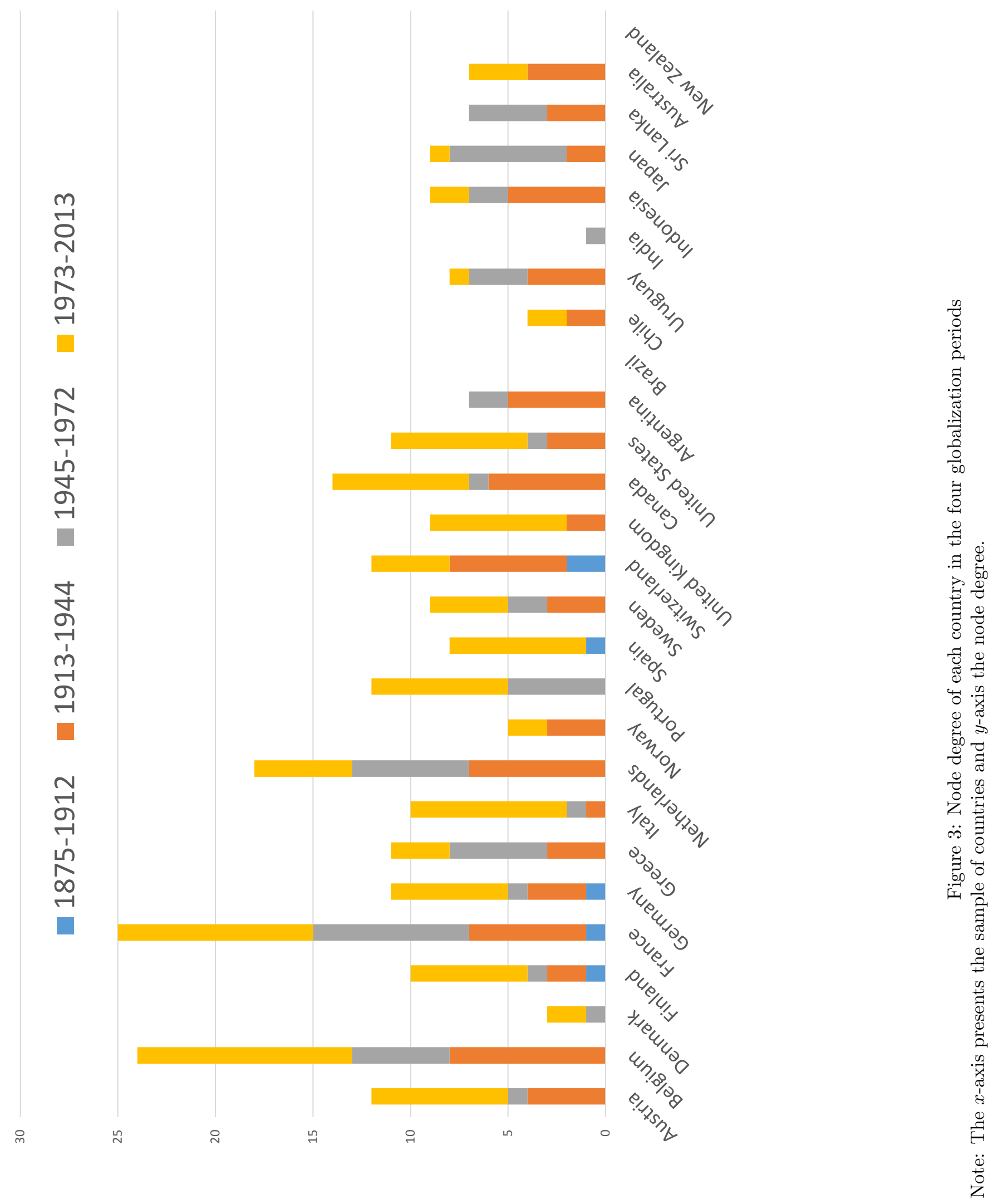
In the first period of focus most nodes are isolated and there are only 2 small subnetworks formed by five European countries with one or two direct neighbors each (see also Figure 2).

The second globalization period of 1913-1944 generally induces a higher degree of business cycle synchronization among the 27 countries with the average node degree increasing from only 0.22 per node to 3.03. However, despite this upward trend, we observe that Denmark, Portugal, Brazil, India and New Zealand resist the general patterns and remain isolated (i.e. they continue to display highly atypical business cycles). Moreover, Spain presents a slightly reverse pattern, getting totally disconnected from the network while it had at least one direct neighbor (France) in the first period.

The third period is associated with an overall reduced business cycle synchronization with the average node degree falling to 2.07. Nevertheless, in this case as well, there are countries that do not follow the general trend. For instance, Denmark and India now become connected to the rest of the network (although with only one neighbor - Sweden and Germany respectively). In addition, France, Greece and Sri Lanka become slightly more connected while finally Portugal and Japan present a rather high increase in their neighboring set (always in relation to the relative de-coupling of business cycles).

Lastly, the final period of floating exchange rates induces business cycle convergence; in fact the highest across the four studied periods. In this period the average node degree rises from 2.07 to 4.14, literally doubling. Exceptions in this instance are Greece, Netherlands, Argentina and Uruguay and in a more extensive degree Japan and Sri Lanka which display a reverse pattern and present diverging business cycle patterns.

Our results are very much in line with those of Artis et al. (2011) and Antonakakis (2012). Artis et al. (2011) examined business cycle synchronisation over the period 18802006 in 25 developed and developing countries, and found that correlations tripled between 1880-1913 and 1919-1939, fell by one-third during the Bretton Woods era and increased by two and a half times during 1973-2006. However, the study of Artis et al. (2011) provide results for the evolution of business cycle synchronisation based on an average measure of correlation, while in our study, each pairwise correlation among the sample of countries is traced and illustrated using this complex network approach. Antonakakis (2012) examined business cycle synchronisation during US recessions in the G7 countries between 1870 and 2011 and found that business cycles co-movements increased to unprecedented levels during the 2007-2009 recession. While our results are also in line with Antonakakis (2012), our analysis provides additional evidence of the changing patterns of synchronisation over the whole period of each globalisation period, not only during recession periods as in Antonakakis $(2012) .^{6}$

\footnotetext{
${ }^{6}$ As an additional robustness check, we performed our analysis using the same sample of countries and years as those in the studies of Artis et al. (2011) and Antonakakis (2012) and our results are qualitatively very similar to those of the aforementioned two studies. We have also compared two of the most significant recessions the global economy has faced over the last 140 years, i.e. the Great Depression and the Great Recession. This analysis revealed that synchronisation was higher during the Great Recession as compared to that during the Great Depression for both developed and developing countries. For the sake of brevity, these results are not presented but available from the authors upon request.
} 
Overall, our findings indicate that despite the general trends in globalization and business cycle synchronization patterns, there are countries that due to the manifestation of idiosyncratic shocks present diverse macro-economic behavior. According to Baldwin and Martin (1999), potential explanations to the changing patterns of international business interdependencies and especially the increased interconnectedness during the latest wave of globalisation are: (i) the enormous short-term capital flows driven by the advancement of information technology. (ii) The outstanding amount of FDI among developed countries in manufacturing as well as service sectors. (iii) The active intra-industry trade promoted by scale economies and product differentiation. (iv) Income convergence among leading nations, coupled with de-industrialization and a rapid speed of industrialization among only some developing countries. (v) Tariff rates, transportation and communication costs have drastically fallen over decades and remained substantially very low in the latest globalisation period. The search and analysis of the reasons that inflicted these diverse patterns fall out of the main scope of this paper. However in the current globally interconnected economic scheme, policy makers could take advantage of these findings to design efficient monetary and financial policies.

\subsection{Developed versus developing economies}

It is noteworthy to examine the patterns of inter-temporal convergence after splitting the sample of countries in two categories according to their level of economic prosperity. In a relative study, Kose et al. (2012) argue that developed economies display increased business cycle convergence while developing economies present business cycle de-coupling. However, our results only partly support their suggestions. By examining Table 5 and Figure 3 we observe that there is no clear trend that could support the convergence hypothesis for the group of developed economies.

Starting with the developed economies, the countries of Belgium, France and the Netherlands are the most well-connected ones throughout the entire sample. Nevertheless this finding provides no proof of convergence per se. The Netherlands, after a sudden integration into the network at the second globalization period, displays a decreasing node degree which signifies a weak de-coupling from the rest of the economies. Greece is another example of an developed economy that displays de-coupling from the general network patterns. In the case of Greece, it should be highlighted that this finding is even more important because the imminent crisis in Greece coupled with its atypical business cycle, deteriorate the effort of alleviating the crisis' effects through an expansionary monetary policy scheme. Lastly, the developed economies of Norway and Australia also both display low node degrees across the whole time sample and moreover signs of business cycle divergence with the rest of the countries.

On the other hand, our findings for the developing economies' group generally confirm the ones of Kose et al. (2012). After an increase in business cycle synchronization in the second globalization period (for Argentina, Uruguay, Indonesia) and in the third period (for India and Sri Lanka), the developing economies display a broad business cycle de-coupling in the recent era of floating exchange rates. A slightly different behavior is displayed by Chile which re-surges and connects with two countries in the last period (from zero in the 
previous one) but this finding is not enough to overturn the general patterns regarding the developing economies.

\section{Conclusion}

In this study, we examined business cycle synchronization from a historical perspective in a set of 27 developed and developing countries. Based on a novel network optimization technique, the Threshold-Minimum Dominating Set (T-MDS), we revealed heterogeneous patterns of international business cycle synchronization during four major globalization periods since the 1870s. More specifically, worldwide business cycles de-coupled during the Gold Standard, followed by a period of increased synchronization during the Great Depression. The Bretton Woods era induced a lower degree of synchronization as compared to the Great Depression. Finally, worldwide business cycle synchronization reached its highest degree during the recent years of floating exchange rates and the Great Recession.

Apart from examining the dynamic, collective evolution of the entire network, we also conducted a node-specific analysis that provided individual inference for each country. This allowed us to observe countries with totally idiosyncratic behavior across the whole studied time sample and to highlight the existence of countries that present reverse patterns to the rest of the network in specific sub-periods.

Finally we examined convergence patterns after separating our sample of countries in developed and developing economies and provided a comparison with the relevant literature. These results could provide valuable insight to politicians and economists in efficient monetary policy making and designing optimal macro-economic strategies.

As an avenue for future research, the proposed methodology of business cycle synchronisation could be performed based on higher frequency data (i.e. quarterly data), and such results compared with those based on annual data so as to check whether aggregation affects the results of the T-MDS.

\section{Acknowledgements}

The authors wish to thank the Editor (Harry Eugene Stanley) and three anonymous reviewers for their very insightful comments and suggestions on a previous version of this paper. Periklis Gogas, Theophilos Papadimitriou and Georgios Sarantitis wish to acknowledge financial support from the European Union (European Social Fund (ESF)) and Greek national funds through the Operational Program 'Education and Lifelong Learning' of the National Strategic Reference Framework (NSRF) - Research Funding Program: THALES (MIS 380292) - Investing in knowledge society through the European Social Fund.

\section{References}

Acemoglu, D., Carvalho, V. M., Ozdaglar, A., Tahbaz-Salehi, A., 2012. The Network Origins of Aggregate Fluctuations. Econometrica 80 (5), 1977-2016.

Allen, F., Gale, D., 2000. Financial Contagion. Journal of Political Economy 108 (1), 1-33. 
Antonakakis, N., 2012. Business Cycle Synchronization during US Recessions since the Beginning of the 1870s. Economics Letters 117 (2), 467-472.

Artis, M., Chouliarakis, G., Harischandra, P. K. G., 2011. Business Cycle Synchronization Since 1880. Manchester School 79 (2), 173-207.

Baldwin, R. E., Martin, P., Jan. 1999. Two Waves of Globalisation: Superficial Similarities, Fundamental Differences. NBER Working Papers 6904, National Bureau of Economic Research, Inc.

Baxter, M., Kouparitsas, M. A., 2005. Determinants of Business Cycle Comovement: A Robust Analysis. Journal of Monetary Economics 52 (1), 113-157.

Boginski, V., Butenko, S., Pardalos, P. M., 2006. Mining Market Data: A Network Approach. Computers \& Operations Research 33 (11), 3171-3184.

Bonanno, G., Caldarelli, G., Lillo, F., Miccichè, S., Vandewalle, N., Mantegna, R. N., 2004. Networks of Equities in Financial Markets. The European Physical Journal, B - Condensed Matter and Complex Systems 38 (2), 363-371.

Cajueiro, D. O., Tabak, B. M., 2008. The Role of Banks in the Brazilian Interbank Market: Does Bank Type Matter? Physica A: Statistical Mechanics and its Applications 387 (27), 6825-6836.

Caraiani, P., 2013. Using Complex Networks to Characterize International Business Cycles. PLoS ONE $8(3), 1-13$.

Cheng, X., Huang, X., Li, D., Wu, W., Du, D. Z., 2003. A Polynomial-time Approximation Scheme for the Minimum-connected Dominating Set in Ad Hoc Wireless Networks. Networks 42 (4), 202-208.

Crucini, M., Kose, A. M., Otrok, C., 2011. What Are the Driving Forces of International Business Cycles? Review of Economic Dynamics 14 (1), 156-175.

Doyle, B. M., Faust, J., 2005. Breaks in the Variability and Comovement of G-7 Economic Growth. The Review of Economics and Statistics 87 (4), 721-740.

Freeman, L. C., 1979. Centrality in Social Networks Conceptual Clarification. Social Networks 1 (3), $215-239$.

Garlaschelli, D., Di Matteo, T., Aste, T., Caldarelli, G., Loffredo, M. I., 2007. Interplay between Topology and Dynamics in the World Trade Web. The European Physical Journal B 57 (2), 159-164.

Gogas, P., 2013. Business Cycle Synchronisation in the European Union: The Effect of the Common Currency. OECD Journal: Journal of Business Cycle Measurement and Analysis 2013 (1), 1-14.

Gomez, D. M., Ortega, G. J., Torgler, B., 2012. Synchronization and Diversity in Business Cycles: A Network Approach Applied to the European Union. CREMA Working Paper Series 2012-01, Center for Research in Economics, Management and the Arts (CREMA).

Guimera, R., Mossa, S., Turtschi, A., Amaral, L. N., 2005. The Worldwide air Transportation Network: Anomalous Centrality, Community Structure, and Cities' Global Roles. Proceedings of the National Academy of Sciences 102 (22), 7794-7799.

Helbling, T., Bayoumi, T., 2003. Are they All in the Same Boat? the 2000-2001 Growth Slowdown and the G-7 Business Cycle Linkages. IMF Working Papers 03/46, International Monetary Fund.

URL http://ideas.repec.org/p/imf/imfwpa/03-46.html

Hill, R. J., 1999. Comparing Price Levels across Countries Using Minimum-Spanning Trees. The Review of Economics and Statistics 81 (1), 135-142.

Imbs, J., 2004. Trade, Finance, Specialization, and Synchronization. The Review of Economics and Statistics 86 (3), 723-734.

Kose, A. M., Otrok, C., Prasad, E., 2012. Global Business Cycles: Convergence OR Decoupling? International Economic Review 53 (2), 511-538.

Kose, A. M., Otrok, C., Whiteman, C. H., 2008. Understanding the Evolution of World Business Cycles. Journal of International Economics 75 (1), 110-130.

Kose, A. M., Prasad, E. S., Terrones, M. E., 2003. How Does Globalization Affect the Synchronization of Business Cycles? American Economic Review 93 (2), 57-62.

Maddison, A., 2003. The World Economy: Historical Statistics. Organization of Economic Cooperation and Development, Paris.

Mantegna, R., 1999. Hierarchical Structure in Financial Markets. The European Physical Journal B - Condensed Matter and Complex Systems 11 (1), 193-197. 
Milgram, S., 1967. The Small World Problem. Psychology Today 2 (1), 60-67.

Otto, G., Voss, G., Willard, L., 2001. Understanding OECD Output Correlations. RBA Research Discussion Papers rdp2001-05, Reserve Bank of Australia.

Pagani, G. A., Aiello, M., 2013. The Power Grid as a Complex Network: A Survey. Physica A: Statistical Mechanics and its Applications 392 (11), 2688-2700.

Papadimitriou, T., Gogas, P., Sarantitis, G. A., 2014. Convergence of European Business Cycles: A Complex Networks Approach. Computational Economics, 1-23.

Papadimitriou, T., Gogas, P., Tabak, B. M., 2013. Complex Networks and Banking Systems Supervision. Physica A: Statistical Mechanics and its Applications 392 (19), 4429-4434.

Schiavo, S., Reyes, J., Fagiolo, G., 2010. International Trade and Financial Integration: A Weighted Network Analysis. Quantitative Finance 10 (4), 389-399.

Schuster, S., Fell, D. A., Dandekar, T., 2000. A General Definition of Metabolic Pathways Useful for Systematic Organization and Analysis of Complex Metabolic Networks. Nature Biotechnology 18 (3), 326-332.

Shen, C., Li, T., 2010. Multi-Document Summarization Via the Minimum Dominating Set. In: Proceedings of the 23rd International Conference on Computational Linguistics. Association for Computational Linguistics. pp. 984-992.

Stock, J. H., Watson, M. W., 2005. Understanding Changes in International Business Cycle Dynamics. Journal of the European Economic Association 3 (5), 968-1006.

Vandewalle, N., Brisbois, F., Tordoir, X., 2001. Self-organized Critical Topology of Stock Markets. Quantitative Finance 1, 372375.

Weng, G., Bhalla, U. S., Iyengar, R., 1999. Complexity in Biological Signaling Systems. Science 284, 92-96.

Wu, J., Li, H., 1999. On Calculating Connected Dominating Set for Efficient Routing in Ad Hoc Wireless Networks. In: Proceedings of the 3rd International Workshop on Discrete Algorithms and Methods for Mobile Computing and Communications. DIALM '99. ACM, New York, NY, USA, pp. 7-14.

Xi, N., Muneepeerakul, R., Azaele, S., Wang, Y., 2014. Maximum Entropy Model for Business Cycle Synchronization. Physica A: Statistical Mechanics and its Applications 413 (C), 189-194. 